\section{Composition at the $\mathrm{CuInSe}_{2}-\mathrm{ZnO}$ interface: copper-depletion induced by diethyl-zinc}

\author{
A. Hofmann, E. Janocha, F. Kelleter and C. Pettenkofer
}

Helmholtz-Zentrum Berlin, Institute for Silicon Photovoltaics, Albert-Einstein-Str. 15, D-12489 Berlin, Germany

Dedicated to Wolfram Jaegermann on the occasion of his $60^{\text {th }}$ birthday.

\begin{abstract}
The interface formation between epitaxial $\mathrm{CuInSe}_{2}(112)$ films and $\mathrm{ZnO}$ deposited by metal-organic MBE is investigated by photoelectron spectroscopy. Reaction of diethyl-zinc with $\mathrm{CuInSe} 2$ leads to the formation of an intrinsic $\mathrm{ZnSe}$ layer and copper-depletion of the interface. This is associated with $\mathrm{Zn}$ doping of the chalcopyrite surface and a Fermi level shift towards the conduction band. The implications on the band alignment are discussed.
\end{abstract}

1. Introduction

One of the basic requirements to obtain highly efficient chalcopyrite solar cells is a buffer layer between the absorber and the sputtered $\mathrm{ZnO}$ window. ${ }^{1}$ For one, the buffer is necessary to prevent shunts between front and back contact, but mainly to provide a good structural and electronic contact between absorber and window material. Hence, the interface should exhibit minimum recombination and current loss and allow for maximum open circuit voltage. ${ }_{4}^{2,3}$

A good structural contact is achieved by using lattice-matched materials and can be further improved by interdiffusion during contact formation. This also results in a good electronic contact since only few structural defect states are present. In addition, the respective positions of electronic bands of the two materials should allow lossless electronic transport and simultaneously not decrease the open circuit voltage. These band offsets are in turn influenced by interface defects and interface dipoles. The detailed progression of valence and conduction band edges is also influenced by interfacial intermixing. ${ }^{4}$

As a model to describe the low interface recombination for chalcopyrite solar cells with $\mathrm{CdS}$ buffer, the concept of a buried homojunction inside the absorber has been discussed. ${ }_{4}^{5,6}$ Here, the Fermi level position is shifted from the valence band (p-type) for the bulk of the absorber towards the conduction band at the interface (n-type). This could be achieved either during the absorber growth process, with $\mathrm{Cu}$-poor conditions during final growth sequence, or induced by contact formation with the buffer. In this case, the buffer material should facilitate the type 
inversion in the absorber near the interface region and thereby shift the charge neutrality region away from the interface into the absorber.

Apparently, the type inversion is associated with a copper-depletion forming a n-type CuInSe layer close to the interface region. For one, surfaces of efficient absorbers are itself copperdepleted with respect to the bulk material. However, recent experiments on polycrystalline and epitaxial chalcopyrite have shown that the intrinsic copper depletion of the surface is

restricted to the top few atomic layers and can be understood as a surface reconstruction. ${ }^{7,8}$ In addition, copper-depletion in $\mathrm{CuInSe}_{2}$ is caused by a self-compensation mechanism induced by n-type doping. For the chemical bath deposited (CBD) CdS buffer, doping of the chalcopyrite by $\mathrm{Cd}_{\mathrm{Cu}}$ defects was observed. ${ }^{9,10}$ The concomitant Fermi level shift leads to spontaneous formation of $\mathrm{V}_{\mathrm{Cu}}$ defects, which compensate for the increased electron density. ${ }^{11}$ This mechanism creates interstitial $\mathrm{Cu}_{\mathrm{i}}$ defects, which show a high mobility due to diffusion in $\mathrm{CuInSe}_{2}{ }^{12}$

Although the CBD-CdS is still the benchmark for high-efficiency cells, Cd-free alternatives that are deposited in a dry vacuum process are being sought, as a complete in line vacuum process without wet-chemical treatments may be achieved ${ }^{15}$. Frequently investigated are $\mathrm{ZnO}$-based semiconductors, which offer the possibility to combine the functionality of a buffer layer and the i-ZnO layer in one film. ${ }^{13}$ Sputtered $(\mathrm{Zn}, \mathrm{Mg}) \mathrm{O}$ layers and ALD-deposited $\mathrm{Zn}(\mathrm{O}, \mathrm{S})$ yielded efficiencies comparable to the $\mathrm{CdS}$ reference. ${ }^{14} \underline{\mathrm{31}}$

In our recent publications, we suggested $\mathrm{ZnO}$ deposited by MOMBE (metal-organic molecular beam epitaxy) as a suitable buffer layer material, since it forms an intrinsic $\mathrm{ZnSe} / \mathrm{ZnS}$ layer in the contact plane between $\mathrm{CuInSe}_{2} / \mathrm{CuInS}_{2}$ absorbers and $\mathrm{ZnO}$ with a favorable band alignment for photovoltaic applications. ${ }^{15},{ }^{16}$ Here, we will further analyze the composition during deposition of MOMBE-ZnO and MBE-ZnSe on $\mathrm{CuInSe}_{2}$ by photoelectron spectroscopy (PES). The focus will be on the formation of copper-poor phases in the chalcopyrite absorber. Implications on the resulting band alignment at the interface are discussed.

\section{Experiment}

$\mathrm{CuInSe}_{2}$ samples were grown by MBE (molecular beam epitaxy) on GaAs(111)A substrates, which were wet-chemically etched prior to insertion into the UHV (ultra-high vacuum) system. Elemental $\mathrm{Cu}$, In and $\mathrm{Se}$ were evaporated from effusion cells. At a substrate temperature of $525^{\circ} \mathrm{C}$, the $(\mathrm{Cu}+\mathrm{In}) / \mathrm{Se}$ ratio is self-adjusting, if Se is provided in excess. The 
$\mathrm{Cu} / \mathrm{In}$ ratio was selected by adjustment of the $\mathrm{Cu}$ flux. Stoichiometric $\mathrm{CuInSe}_{2}$ surfaces and $\mathrm{Cu}$-poor surfaces of the $\mathrm{CuIn}_{3} \mathrm{Se}_{5}$ defect compound could thus be obtained.

$\mathrm{ZnO}$ films were deposited by metal-organic MBE (MOMBE) from gaseous precursors DEZ (diethyl-zinc) (Sigma Aldrich) and water_ultra-purified and vacuum distiiled) at chalcopyrite substrate temperatures ranging from $325-400^{\circ} \mathrm{C}$. The DEZ and $\mathrm{H}_{2} \mathrm{O}$ partial pressures were $2 \times 10^{-6}$ mbar and $8 \times 10^{-6}$ mbar, respectively. ZnSe was deposited by evaporation of the compound from an effusion cell (MBE) at substrate temperatures of 300 and $350{ }^{\circ} \mathrm{C}$.

To ensure contamination free sample surfaces, all preparation and analysis were carried out in our integrated UHV system with a base pressure in the $10^{-10}$ mbar range. The single crystalline structure and surface order were confirmed by LEED (low-energy electron diffraction). For sample characterization, depth profiles and band alignment measurements we used photoelectron spectroscopy with $\mathrm{MgK}_{a}$, mono- $\mathrm{AlK}_{a}$ and $\mathrm{HeI}$ radiation and a SpecsPhoibos 150 electron analyzer equipped with a delay line detector.

$\underline{\mathrm{Cu} / \mathrm{In} \text { ratios were obtained by fitting the appropriate lines (see Fig } 1 \text { ) and the relation }}$ $\frac{C_{C u}}{C_{I n}}=\frac{I_{C u}}{I_{I n}} \cdot \frac{S_{C u}}{S_{I n}}$ with $\underline{\mathrm{S}}_{\underline{C u}}=3.55$ and $\mathrm{S}_{\underline{\underline{I}} \underline{ }}=4.36$ for $\mathrm{AlK}_{\underline{\mathrm{a}}} \underline{\text { radiation }}{ }^{32}$. Angular dependent spectra were recorded by rotating the sample manipulator. The mean elastic free path changed from $2.6 \mathrm{~nm}$ to $0.89 \mathrm{~nm}$ for $\mathrm{Cu}$ and from 3.2 to $1.2 \mathrm{~nm}$ respectively for In changing the escape angle from $0^{\circ}$ to $70^{\circ}$. The accuracy of the manipulator was checked by recording the ARUPS data for the Shokley surface state $\mathrm{S} 1$ of a $\mathrm{Cu}(111)$ sample to be better than $0.3^{\circ}$

GaAs (111) substrates were cleaned and etched in a $\mathrm{H}_{2} \underline{\mathrm{SO}}_{4}-\mathrm{HCl}_{2} \mathrm{H}_{2} \mathrm{O}(2: 2: 5)$ solution for $20 \mathrm{~min}$. at $50^{\circ} \mathrm{C}$ and a sulfur termination in $\left(\mathrm{NH}_{4}\right)_{2} \mathrm{~S}$ solution for $30 \mathrm{~min}$ at $60^{\circ} \mathrm{C}$.

On the $\mathrm{GaAs}(111)$ surface, $\mathrm{CuInSe}_{2}$ grows along its (112) direction and therefore with its low-energy surface. On flat substrates, these samples exhibit rotational domains, as indicated by the hexagonal LEED pattern. Near-stoichiometric surfaces show a $c(4 \times 2)$ reconstruction $\frac{8}{40}$ indicating the chalcopyrite surface order (see Fig. 1). For copper-poor samples, the chalcopyrite surface order is absent, indicating short-range order of the cation sublattice.

For the band alignment and interface formation experiment, the $\mathrm{ZnO} / \mathrm{ZnSe}$ films were deposited stepwise onto the $\mathrm{CuInSe}_{2}(112)$ substrate and the samples were subsequently characterized after each deposition cycle.

3. Results

3.1 $\mathrm{ZnO}$ buffer layer by MOMBE 
The core level photoemission lines in the course of $\mathrm{ZnO}$ deposition by MOMBE are shown in Fig. 2. It is apparent that $\mathrm{Zn}$ is present from the first deposition step on, while no oxygen is observed for the first two growth cycles. Like we reported earlier for the $\mathrm{CuInSe}_{2}(112)$ surface, this behavior can be understood in terms of an ultra-thin ZnSe buffer formed at the chalcopyrite surface by reaction of DEZ with the substrate chalcogenide. $\frac{16}{2}$ This is indicated by the absence of the oxygen emission peak and the evolution of the $\mathrm{Zn}$ Auger parameter $\alpha_{\mathrm{Zn}}$. Here, the binding energy of the $\mathrm{Zn} 2 \mathrm{p}_{3 / 2}$ peak and the kinetic energy of the $\mathrm{Zn}$ LMM Auger emission are added, to give a more precise measure for the chemical environment of $\mathrm{Zn}$ atoms. A shift of $\alpha_{Z_{n}}$ from $2011.9 \mathrm{eV}$ typical for $\mathrm{ZnSe}$ to $2010.1 \mathrm{eV}$ which is indicative of $\mathrm{ZnO}$ is observed. No $\mathrm{C} 1 \mathrm{~s}$ contaminations are observed after MOMBE deposition, indicating a clean reaction of the precursors at the surface ${ }^{33}$.

The reaction of DEZ vapor with the chalcopyrite surface at elevated temperatures $(\mathrm{T}=325-$ $\left.450^{\circ} \mathrm{C}\right)$ is well-established for $\mathrm{CuInS}_{2}(112) \stackrel{15}{\sim}$ poly-CuInS${ }_{2}, \mathrm{CuInSe}_{2}(112)$ and (001) $\frac{16}{r}$ substrates. Depending on the details of substrate composition and process parameters this $\mathrm{ZnS} / \mathrm{ZnSe}$ layer reaches a thickness of $0.5-1.5 \mathrm{~nm}$, as determined from the attenuation of the In3d signal.

The growth mode of $\mathrm{ZnSe} / \mathrm{ZnO}$ can be monitored with LEED analysis. For stoichiometric chalcopyrite, the superstructure spots indicating the chalcopyrite surface order vanish after deposition of the $\mathrm{Zn}$ (Fig. 1). The resulting hexagonal pattern shows sharp spots indicative of epitaxial growth. This can be expected due to the close lattice constants of $\mathrm{CuInSe}_{2}$ with 5.78 $\AA$ and $5.67 \AA$ for $\mathrm{ZnSe}$, which results in a small lattice mismatch of $1.9 \%$. The vanishing of superstructure spots could be interpreted as the formation of a $\mathrm{ZnSe}$ layer without long-range surface reconstruction order. However, for a $\mathrm{Zn}$ coverage in the sub-monolayer range, the absence of a superstructure can be understood in terms of a Cu-poor surface with $\mathrm{CuIn}_{3} \mathrm{Se}_{5}$ composition further denoted as ordered defect compound (ODC).

This type of compositional change, namely the reduction of the $\mathrm{Cu} / \mathrm{In}$ ratio near the absorber/buffer interface, shall be considered here. The reaction of DEZ with the Se constitutes one mechanism of intermixing at the interface. Interaction of the water provided in the MOMBE process with chalcopyrite is apparently weak. For further interface reaction analysis, we will consider the composition in the absorber during $\mathrm{ZnSe} / \mathrm{ZnO}$ layer growth.

For this purpose, we analyze the $\mathrm{Cu} / \mathrm{In}$ ratio of photoemission intensities. Due to the use of $\mathrm{MgK}_{a}$ radiation, electrons ejected from $\mathrm{Cu} 2 \mathrm{p}_{3 / 2}$ and $\mathrm{In} 3 \mathrm{~d}_{5 / 2}$ exhibit different inelastic mean free paths $\lambda$ and therefore, according to the Lambert-Beers law $\mathrm{I}=\mathrm{I}_{0} \mathrm{e}^{-\mathrm{d} /}$, are not uniformly
Christian Pettenkofer 20.1.14 15:32 Gelöscht: ${ }^{16}$

Christian Pettenkofer 6.11.14 16:10

Formatiert: Schriftart:12 pt, Schriftfarbe:

Text 1, Hochgestellt

Christian Pettenkofer 20.1.14 15:04

Gelöscht: This

Christian Pettenkofer 20.1.14 15:04

Gelöscht: s

Christian Pettenkofer 20.1.14 15:32

Gelöscht: ${ }^{16}$

Christian Pettenkofer 6.11.14 16:10

Formatiert: Schriftart:12 pt, Schriftfarbe:

Text 1, Hochgestellt

Christian Pettenkofer 20.1.14 15:32

Gelöscht: ${ }^{15}$

Christian Pettenkofer 6.11.14 16:10

Formatiert: Schriftart:12 pt, Schriftfarbe: Text 1, Hochgestellt 
damped by the $\mathrm{ZnSe} / \mathrm{ZnO}$ layer. Assuming a uniform top layer of thickness d, the $\mathrm{Cu} / \mathrm{In}$

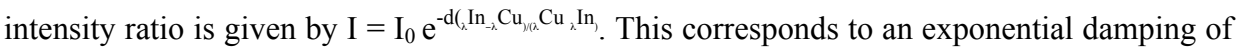
the $\mathrm{Cu} / \mathrm{In}$ intensity with increasing $\mathrm{ZnSe} / \mathrm{ZnO}$ layer thickness, provided that the actual concentration ratio of $\mathrm{Cu}$ to $\mathrm{In}$ in the underlying absorber remains constant.

The $\mathrm{Cu} / \mathrm{In}$ intensities for $\mathrm{CuInSe}_{2}(112)$ are plotted in Fig. 3 versus the $\mathrm{ZnSe} / \mathrm{ZnO}$ layer thickness for MOMBE-ZnO growth on $\mathrm{CuInSe}_{2}$ substrates. The layer thickness was determined from the attenuation of the In3d core level signal. The following features can be identified: 1 . The $\mathrm{Cu} / \mathrm{In}$ ratio drops suddenly for small amounts of $\mathrm{Zn}$ coverage for $\mathrm{CuInSe} \mathrm{S}_{2}$ surface compositions around the stoichiometric point. This drop cannot be explained by the non-uniform damping of photoemission intensities, but is rather an indication of a change in the composition near the surface. 2. For substrates with ODC surface composition, the $\mathrm{Cu} / \mathrm{In}$ intensities evolve according to the theoretical curve for uniform damping and unchanged composition. 3. By deposition of $\mathrm{Zn}$ from MOMBE, the $\mathrm{Cu} / \mathrm{In}$ ratio near the surface/interface for $\mathrm{CuInSe} e_{2}$ approaches the curve for $\mathrm{CuIn}_{3} \mathrm{Se}_{5}$. The data presented here were recorded for the $\mathrm{CuInSe}_{2}(112)$. Note that the same behavior of the $\mathrm{Cu} / \mathrm{In}$ ratio is observed for $\mathrm{ZnO}$ deposition on the $\mathrm{CuInSe}_{2}(001)$ surface. $\frac{24}{4}$ Therefore, the copper depletion mechanism is regarded independent from the surface orientation.

The conclusion is the following: Deposition of small amounts of $\mathrm{Zn}$ on $\mathrm{CuInSe}_{2}$ by exposure to $\mathrm{DEZ}$ at elevated temperatures $\left(\mathrm{T} \approx 350^{\circ} \mathrm{C}\right)$ leads to a reduction in $\mathrm{Cu}$ concentration near the surface and consequently the interface with $\mathrm{ZnSe} / \mathrm{ZnO}$. Here, the $\mathrm{Cu} / \mathrm{In}$ ratio as observed in XPS approaches values that are indicative of the copper-deficient defect phase $\mathrm{CuIn}_{3} \mathrm{Se}_{5}$ (ODC).

$\mathrm{Zn}$ deposition onto the $\mathrm{CuInSe}_{2}$ surface leads to band bending and therefore shifts the Fermi level position in the band gap. This can be understood in terms of n-type doping via $\mathrm{Zn}_{\mathrm{Cu}}$ defects which is associated with a simultaneous formation of a $\mathrm{ZnSe}$ layer at the surface. The Fermi level shift towards the conduction band minimum (CBM) results in a lowering of the defect formation energies. Calculations by Persson et al. ${ }^{17}$ revealed that the energy for $\mathrm{V}_{\mathrm{Cu}}$ formation becomes exothermal for a Fermi level position at $0.95 \mathrm{eV}$ from the VBM or equally $0.09 \mathrm{eV}$ form the CBM. This leads to spontaneous formation of $\mathrm{V}_{\mathrm{Cu}}$ defects and the associated diffusion of interstitial $\mathrm{Cu}$ away from the surface explains the observed copper depletion. This mechanism was first observed by Klein et al. on cleaved $\mathrm{CuInSe}_{2}$ single crystals after deposition of CdS and $\mathrm{Na} \cdot \frac{11}{1} 18$

In order to obtain the Fermi level position in the band gap after exposure of $\mathrm{CuInSe}_{2}$ to DEZ, we add the position of the VBM for the bare substrate to the band bending induced by $\mathrm{Zn}$ 
deposition. Results obtained for the different near-stoichiometric samples are $1.02 \mathrm{eV}$ and $0.93 \mathrm{eV}$ for the In-rich and $\mathrm{Cu}$-rich surface, respectively. This agrees nicely with the theoretical value for the threshold of spontaneous defect creation.

\subsection{ZnSe buffer layer by MBE (PVD)}

A similar experiment was conducted in order to elucidate the reaction of $\mathrm{Zn}$ with the substrate. Here, $\mathrm{Zn}$ was not provided in form of a reactive organo-metallic compound, but by evaporation from the $\mathrm{ZnSe}$ compound. $\mathrm{ZnSe}$ sublimes dissociatively, forming $\mathrm{Zn}$ and $\mathrm{Se}_{2}$ in the gas phase. ${ }^{19}$ Therefore, roughly stoichiometric amounts of elemental $\mathrm{Zn}$ and Se impinge on the substrate surface. To facilitate epitaxial growth of $\mathrm{ZnSe}$ and for comparison with the MOMBE process, the substrate temperature was set to $300^{\circ}$ for the $\mathrm{Cu}$-rich and $350^{\circ} \mathrm{C}$ for the In-rich sample.

To analyze the effect of elemental $\mathrm{Zn}$ on the $\mathrm{CuInSe}_{2}(112)$ surface, we first consider the $\mathrm{Zn}$ Auger parameter. $\alpha_{\mathrm{Zn}}$ remains effectively unchanged throughout the experiment at values around $2011.9 \mathrm{eV}$ and is indicative of $\mathrm{Zn}-\mathrm{Se}$ bonds. For increasing $\mathrm{ZnSe}$ layer thickness, the chalcopyrite superstructure spots in the LEED pattern vanish (Fig. 1).

Now, the evolution of the $\mathrm{Cu} / \mathrm{In}$ ratio during the experiment shall be considered, to see if a $\mathrm{Cu}$ depletion similar to the MOMBE process occurs. During the first deposition steps, a slight reduction of the $\mathrm{Cu} / \mathrm{In}$ compared to the uniform damping curve is observed. Hence, the onset of a $\mathrm{Cu}$ depletion is visible, albeit not as pronounced as for the MOMBE process, and $\mathrm{Cu} / \mathrm{In}$ does not approach the ODC value. From $\mathrm{ZnSe}$ layer thicknesses of more than $\approx 1 \mathrm{~nm}$ on, $\mathrm{Cu} / \mathrm{In}$ rises above the uniform damping curve. Even for $\mathrm{ZnSe}$ films that are thick compared to the XPS information depth, a $\mathrm{Cu}$ signal is still measureable. This indicates a (temperature driven) $\mathrm{Cu}$ migration from $\mathrm{CuInSe}_{2}$ into the $\mathrm{ZnSe}$ layer at elevated temperatures. XPS depth profile measurements show that $\mathrm{Cu}$ concentration is enhanced at the surface of $\mathrm{ZnSe}$. We therefore conclude that the $\mathrm{Cu}$ depletion near the $\mathrm{CuInSe}_{2} / \mathrm{ZnSe}$ interface is superimposed with $\mathrm{Cu}$ diffusion into the $\mathrm{ZnSe}$ layer and segregation of a $\mathrm{Cu}-\mathrm{Zn}$-Se compound at the surface. Hence, the formation of an ODC near the interface could not be as clearly identified as for the case of MOMBE-ZnO deposition.

\subsection{Concentration depth profile}

In order to further analyze the copper depletion induced by the DEZ, compositional depth profiles have been recorded with angle-resolved XPS (x-ray PES). By variation of the detection angle $\theta$ relative to the surface normal, the surface sensitivity of XPS is increased 
according to $\lambda(\theta)=\lambda_{0} \cos \theta$. The $\mathrm{Cu} / \mathrm{In}$ ratio profile for the bare absorber in Fig. 4 shows a strong angular dependence. Since the observed reduction of $\mathrm{Cu} / \mathrm{In}$ occurs within an effective change in information depth from $1.5-0.5 \mathrm{~nm}$, this behavior was explained as a copper-poor surface reconstruction of the $\mathrm{CuInSe}_{2}$ (112) surface. $\frac{8}{20}{ }^{20}$ Here, the top atomic layer of the cation-terminated surface is entirely depleted of $\mathrm{Cu}$, which is equal to the formation of $2 \mathrm{~V}_{\mathrm{Cu}}$ per surface unit cell. ${ }^{21}$

After exposure to DEZ at $400^{\circ} \mathrm{C}$ substrate temperature, this curve appears shifted to lower $\mathrm{Cu} / \mathrm{In}$ values. For one, this proofs the strong reduction of the overall $\mathrm{Cu}$ concentration due to the reaction with DEZ. Second, a strong copper gradient within a few atomic layers from the surface is still present. This means that a copper depletion of the near-surface region exists together with copper-poor interface structure. The formation of $\mathrm{ZnSe}$ bonds in the course of $\mathrm{Zn}$ deposition indicates that vacant $\mathrm{Cu}$ sites at the surface are filled by $\mathrm{Zn}$ atoms, thereby increasing the electron concentration at the surface. This could lead to a pinning of the Fermi level near the conduction band at the $\mathrm{CuInSe}_{2} / \mathrm{ZnSe}$ interface.

\section{Discussion}

Doping of the CuInSe $\mathrm{H}_{2}$ surface is also observed for CBD-CdS buffer layers. ${ }^{22}$ PES depth profiles show that $\mathrm{Cd}$ is restricted to first atomic layers and depends on the availability of free sites, namely $\mathrm{V}_{\mathrm{Cu}}$. Therefore, one has to consider the interplay between doping, position of the Fermi level and defect formation. Doping shifts the Fermi level and causes additional copper depletion. The resulting stoichiometry for exposure to DEZ at elevated temperatures is that of the ordered defect compound. Therefore, we suggest the following structure for the $\mathrm{CuInSe}_{2}$ $\mathrm{ZnO}$ interface (see Fig. 5): near the interface, the absorber is copper depleted with ODC composition and presumably $\mathrm{Zn}$-doped, this region is termed $\mathrm{Zn}: \mathrm{CuIn}_{3} \mathrm{Se}_{5}$. The attenuation of both the $\mathrm{Cu}$ and In signal before oxygen deposition requires the presence of a $\mathrm{ZnSe}$ phase on top of the copper-depleted region. Finally, pure $\mathrm{ZnO}$ is deposited in the MOMBE process. Annealing experiments reported earlier show that there is partial diffusion of $\mathrm{In}$ into the $\mathrm{ZnO}$ window. $^{23}$

With the knowledge about interdiffusion and the different phases present at the $\mathrm{CuInSe}_{2}-\mathrm{ZnO}$ interface, the complete band diagram can be constructed. Here, we use values for the individual interfaces as determined from PES according to our previous publications. $\frac{16}{a . p} 24,25$ Special care was taken to analyze the VBM of epitaxial CuInSe $\mathrm{Ce}_{2}$ correctly by considering the experimental valence band structure. ${ }^{26}$ The valence band offset between stoichiometric $\mathrm{CuInSe}_{2}$ and the ODC was determined in a separate experiment by direct growth of $\mathrm{Cu}$-poor
Christian Pettenkofer 6.11.14 16:10

Formatiert: Schriftart:12 pt

Christian Pettenkofer 20.1.14 15:32

Gelöscht: Fig. 4

Christian Pettenkofer 6.11.14 16:10

Formatiert: Schriftart:12 pt,

Rechtschreibung und Grammatik prüfen

Christian Pettenkofer 6.11.14 16:10

Formatiert: Schriftart:12 pt, Schriftfarbe: Text 1, Hochgestellt

Christian Pettenkofer 20.1.14 15:32 Gelöscht: ${ }^{8}$ 
material on a CuInSe 2 (112) substrate. By application of the transitivity rule, we obtain valence band discontinuities $\Delta \mathrm{E}_{\mathrm{V}}$ of $0.78 \mathrm{eV}$ and $2.23 \mathrm{eV}$ for $\mathrm{CuInSe}_{2} / \mathrm{ZnSe}$ and $\mathrm{CuInSe}_{2} / \mathrm{ZnO}$ interface, respectively. These results also agree nicely with theoretical values for the respective interfaces. ${ }^{27},{ }^{28}$ However, it should be noted that, due to the intermixing at elevated temperatures, the interfaces are not atomically sharp. From the band diagram in Fig. 6 , it is obvious that the conduction band lineup is favorable for electronic transport from the absorber to the $\mathrm{ZnO}$ window if the $\mathrm{ZnSe}$ layer remains thin enough for electrons to tunnel through.

Apparently, the choice of buffer layer material and deposition process severely influences the composition and diffusion properties of the interface. Hereby, one can either promote or hinder copper depletion of the interface region. There are indications that copper accumulation, like it was observed for sputtered $(\mathrm{Zn}, \mathrm{Mg}) \mathrm{O}$ buffer layers reduces cell performance. ${ }^{29}$ Most of the models describing highly efficient cells work with a buried p-nhetero-junction inside the chalcopyrite absorber. The question is if a copper-depleted layer is necessary for the buried junction and to what extent this depletion is beneficial for the cell performance. Vacuum deposition methods offer a variety of possibilities to adjust the interface chemistry by the type of deposition process and process parameters. Recent investigations on $\mathrm{ZnO}$ buffer layers deposited with ALD indicate a copper-depletion of the interface at lower process temperatures and derived from Auger-parameter data an interface layer of $\mathrm{ZnIn}_{2} \underline{S e}_{4}$ is proposed, which is situated between the ODC and the ZnSe layer. ${ }^{30}$ Therefore, it would be insightful to study different deposition methods or the influence of the process temperature on copper-depletion to optimize the interface properties.

We have shown that a clear copper-depletion of the interface can be evoked by exposure of near-stoichiometric $\mathrm{CuInSe}_{2}$ surfaces to DEZ at elevated temperatures. Therefore, interface properties can be adjusted deliberately by choice not only by the type of buffer material but also by the process type and processing parameters.
Christian Pettenkofer 6.11.14 16:10

Formatiert: Rechtschreibung und

Grammatik prüfen

Christian Pettenkofer 20.1.14 15:32

Gelöscht: Fig. 6 


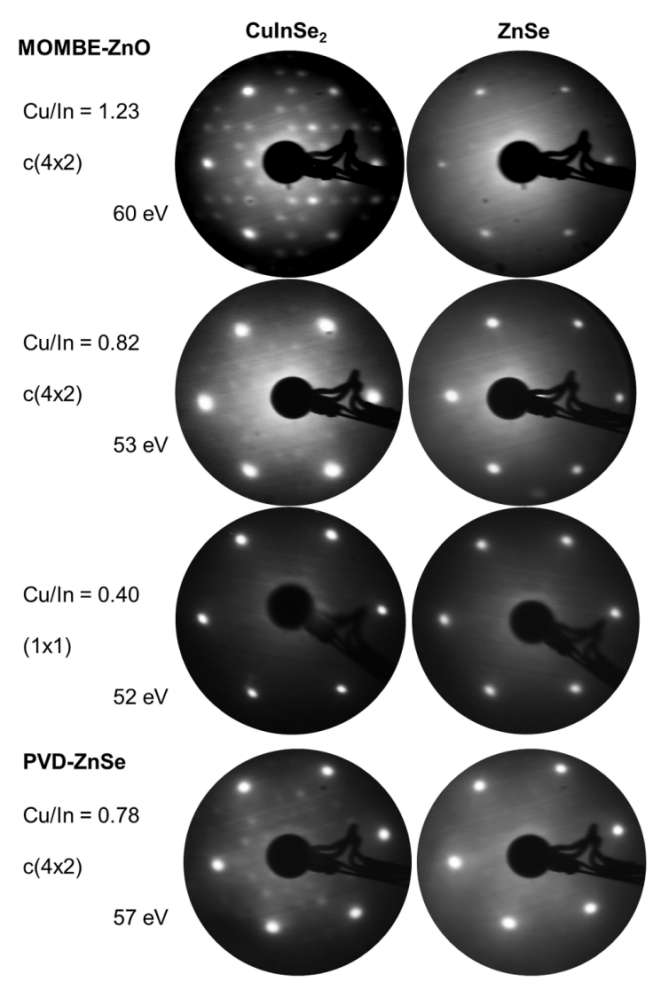

Fig. 1 LEED images for $\mathrm{CuInSe}_{2}(112)$ substrates of varying $\mathrm{Cu} / \mathrm{In}$ stoichiometry before and after deposition of a thin $\mathrm{ZnSe}$ layer as a interface reaction by $\mathrm{ZnO}$ MOMBE and ZnSe-MBE. The chalcopyrite superstructure of near-stoichiometric samples vanishes due to $\mathrm{Zn}$ deposition. 

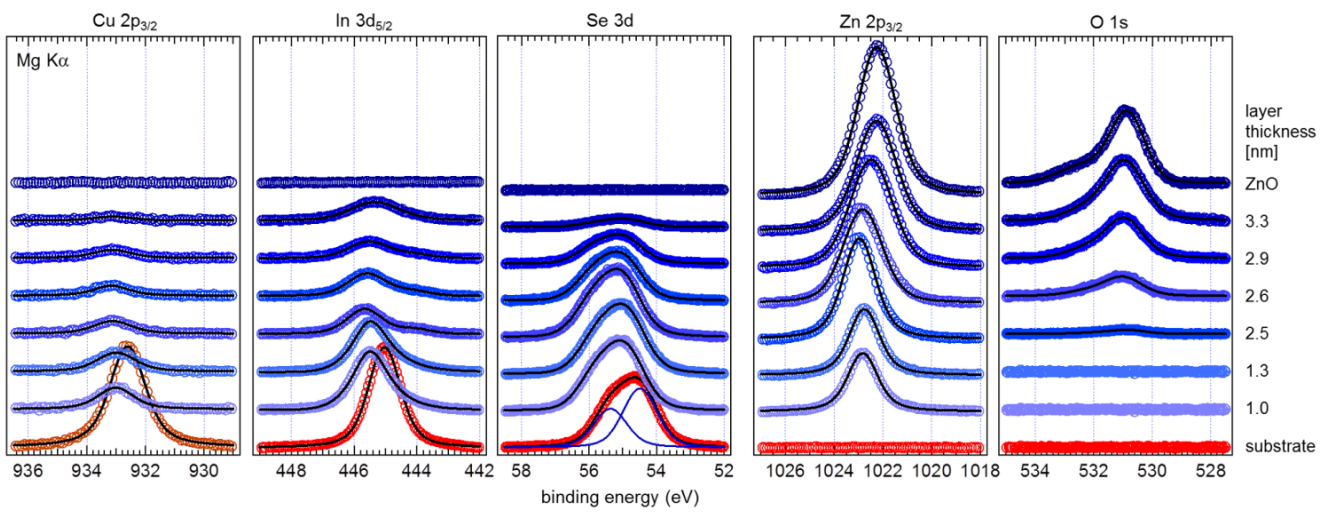

Fig. $2 \mathrm{X}$-ray photoemission spectra of the main core levels after each MOMBE-ZnO deposition step on a $\mathrm{CuInSe}_{2}(112)$ film. Note that no oxygen signal is present for the first two $\mathrm{ZnO}$ deposition steps. Layer thickness is evaluated from the attenuation of the In signal according to Lambert-Beer law.

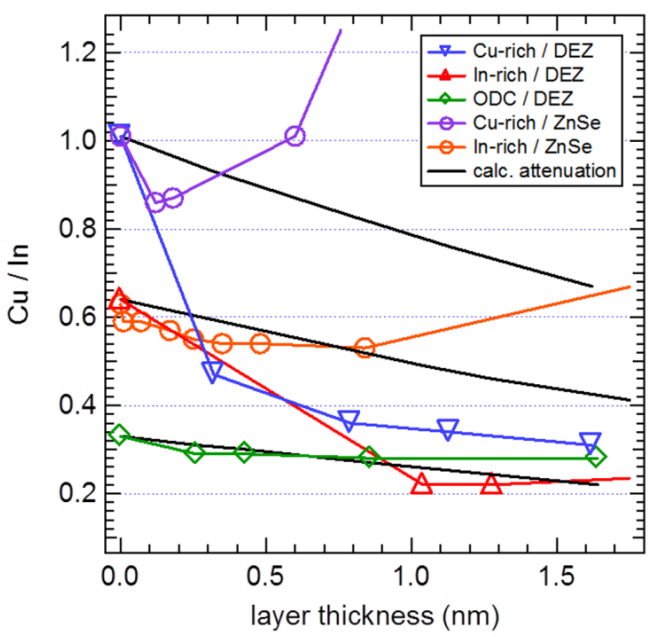

Fig. 3 Evolution of the $\mathrm{Cu} / \mathrm{In}$ signal ratio during MOMBE-ZnO (DEZ) and PVD-ZnSe grwoth on CuInSe substrates with varying stoichiometry derived from PES data in normal emission, layer thickness is derived from the attenuation of the In signal. The black lines indicate the progression that is expected for uniform growth without diffusion or intermixing. Significant deviations are observed for near-stoichiometric samples. 


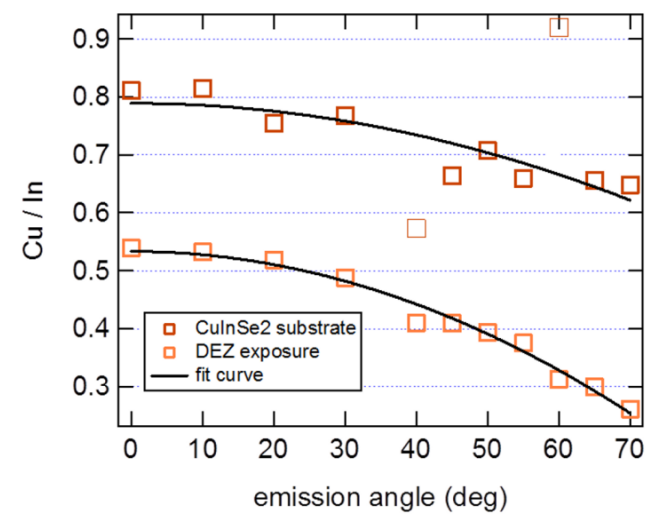

Fig. 4 Depth profile of the $\mathrm{Cu} / \mathrm{In}$ ratio recorded by angleresolved XPS using $\mathrm{AlK}_{u}$ radiation. The bare $\mathrm{CuInSe}_{2}$ substrate shows a copper-poor surface, indicated by a reduction of $\mathrm{Cu} / \mathrm{In}$ for larger emission angles (increased surface sensitivity). After exposure to diethyl-zinc and formation of a $1.3 \mathrm{~nm} \mathrm{ZnSe}$ layer, the curve appears shifted to lower $\mathrm{Cu} / \mathrm{In}$ values due to copper-depletion and ODC formation.

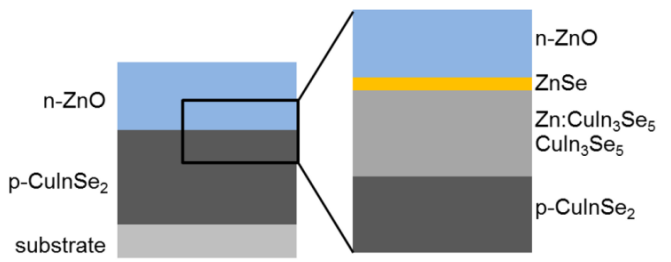

Fig. 5. Schematic of the detailed composition at the $\mathrm{CuInSe}_{2} / \mathrm{ZnO}$ interface.

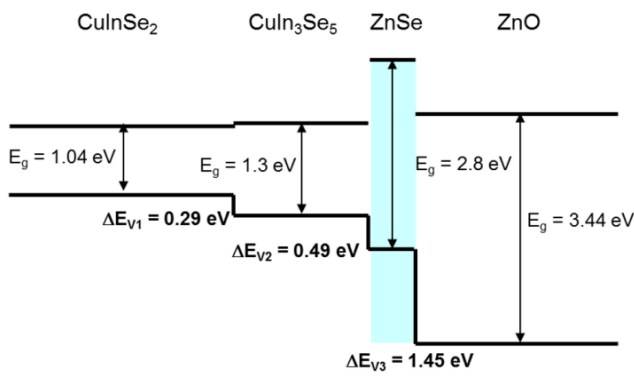

Formatiert: Schriftart:11 pt, Nicht Fett,

Schriftfarbe: Text 1, Hochgestellt

Christian Pettenkofer 20.1.14 15:32

Gelöscht: ${ }^{16}$

Christian Pettenkofer 6.11.14 16:10

Formatiert: Schriftart:11 pt, Nicht Fett,

Schriftfarbe: Text 1, Hochgestellt

Christian Pettenkofer 20.1.14 15:32

Gelöscht: ${ }^{24}$

Fig. 6 Resulting band diagram for the $\mathrm{CuInSe}_{2} / \mathrm{ZnO}$ interface. Valence band discontinuities were taken from

| our previous publications. $\frac{16}{24}$ Conduction band offsets

Christian Pettenkofer 6.11.14 16:10

Formatiert: Schriftart:11 pt, Nicht Fett, Schriftfarbe: Text 1, Hochgestellt 
were calculated with the use of literature values of band gap energies.

\footnotetext{
${ }^{1}$ S. Siebentritt, U. Rau, Wide-Gap Chalcopyrites, Springer Berlin-Heidelberg (2006).

${ }^{2}$ R. Klenk, Thin Solids Film 387, 135 (2001).

${ }^{3}$ U. Rau, H.W. Schock, Appl. Phys. A 69, 131 (1999).

${ }^{4}$ M. Morkel, L. Weinhardt, B. Lohmüller, C. Heske, E. Umbach, W. Riedl, S. Zweigart, F. Karg, Appl. Phys. Lett. 79, 4482 (2001).

${ }^{5}$ K. Ramanathan, R. Noufi, J. Granata, J. Webb, J. Keane, Sol. Energy Mater. Sol. Cells 55, 15 (1998).

${ }^{6}$ C. S. Jiang, F. S. Hasoon, H. R. Moutinho, H. A. Al-Thani, M. J. Romero, M. M. Al-Jassim, Appl. Phys. Lett. 82, 127 (2003).

${ }^{7}$ H. Mönig, C.-H. Fischer, R. Caballero, C. Kaufmann, N. Allsop, M. Gorgoi, R. Klenk, H.-W. Schock, S. Lehmann, M. Lux-Steiner, I. Lauermann. Acta Materialia, 57(12), 3645 (2009).

${ }^{8}$ A. Hofmann, C. Pettenkofer, Surface Science 606, 1180 (2012).

${ }^{9}$ C. Heske, D. Eich, R. Fink, E. Umbach, T. van Buuren, C. Bostedt, L. J. Terminello, S. Kakar, M. M. Grush, T. A. Callcott, F. J. Himpsel, D. L. Ederer, R. C. C. Perera, W. Riedl, F. Karg, Appl. Phys.
} Lett. 74, 1451(1999).

${ }^{10}$ O. Cojocaru-Mirédin, P. Choi, R. Wuerz, D. Raabe, Appl. Phys. Lett 98, 103504 (2011).

${ }^{11}$ A. Klein, W. Jaegermann, Appl. Phys. Lett. 74, 2283 (1999).

${ }^{12}$ J. Pohl, A. Klein, K. Albe, Phys. Rev. B 84, 121201 (2011).

${ }^{13}$ A. Grimm, D. Kieven, R. Klenk, I. Lauermann, A. Neisser, T. Niesen, J. Palm, Thin Solid Films 520, 1330 (2011).

${ }^{14}$ C. Platzer-Björkman, T. Törndahl, D. Abou-Ras, J. Malmström, J. Kessler, L. Stolt, J. Appl. Phys. 100, 044506 (2006).

${ }^{15}$ S. Andres, C. Lehmann, C. Pettenkofer, Thin Solid Films 518, 1032 (2009).

${ }^{16}$ A. Hofmann, C. Pettenkofer, Appl. Phys. Lett. 98, 113503 (2011).

${ }^{17}$ C. Persson, Y.-J- Zhao, S. Lany, A. Zunger, Phys. Rev. B 72, 0352111 (2005).

${ }^{18}$ A. Klein, T. Schulmeyer, Wide-Gap Chalcopyrites, Springer Berlin-Heidelberg (2006).

${ }^{19}$ R.M. Park, N.M. Salansky, Appl. Phys. Lett. 44, 249 (1984).

${ }^{20}$ D. Liao, A. Rockett. Appl. Phys. Lett. 82(17), 2829 (2003).

${ }^{21}$ S. B. Zhang, S.-H. Wei. Phys. Rev. B 65(8), 081402 (2002).

${ }^{22}$ D. Liao, A. Rockett. J. Appl. Phys. 93(11), 9380 (2003).

${ }^{23}$ C. Pettenkofer, A. Hofmann, W. Bremsteller, C. Lehmann, F. Kelleter, Ultramicroscopy 119,(2012). pp. 102-105

${ }^{24}$ A. Hofmann, Electronic structure of epitaxial chalcopyrite films and heterocontacts relevant to photovoltaics, PhD thesis, BTU Cottbus (2012).

${ }^{25}$ A. Hofmann, C. Pettenkofer, Appl. Phys. Lett. 101, 062108 (2012)

${ }^{26}$ A. Hofmann, C. Pettenkofer, Phys. Rev. B 84(11), 115109 (2011).

${ }^{27}$ W. Mönch, Appl. Phys. A 87, 359-366 (2007).

${ }^{28}$ S.-H. Wei, A. Zunger, Appl. Phys. Lett. 72, 2011 (1998).

${ }^{29}$ I. Lauermann, Ch. Loreck, A. Grimm, R. Klenk, H. Mönig, M.Ch. Lux-Steiner, Ch.-H. Fischer, S. Visbeck, T.P. Niesen, Thin Solid Films, 515, 6015 (2007).

${ }^{30}$ E. Janocha, C. Pettenkofer, Radiation Physics and Chemistry 93, (2013), pp.72-76,

${ }^{31}$ Scheer, Roland / Schock, Hans-Werner Chalcogenide Photovoltaics Physics, Technologies, and Thin Film Devices Wiley VCH, ISBN 978-3-527-31459-1, and references there in

\begin{tabular}{l}
\hline Christian Pettenkofer 20.1.14 15:19 \\
\hline Gelöscht: (2012). \\
\hline Christian Pettenkofer 20.1.14 15:19 \\
Gelöscht: accepted. \\
\hline Christian Pettenkofer 20.1.14 15:18 \\
\hline Gelöscht: in press \\
\hline Christian Pettenkofer 20.1.14 14:18 \\
\hline $\begin{array}{l}\text { Formatiert: Schriftart:Times New Roman, } \\
11 \text { pt }\end{array}$ \\
\hline Christian Pettenkofer 20.1.14 14:18 \\
\hline $\begin{array}{l}\text { Formatiert: Schriftart:Times New Roman, } \\
11 \text { pt, Nicht Fett }\end{array}$ \\
\hline Christian Pettenkofer 20.1.14 14:18 \\
\hline $\begin{array}{l}\text { Formatiert: Schriftart:Times New Roman, } \\
11 \text { pt }\end{array}$ \\
\hline
\end{tabular}


32 J.F. Moulder, W.S. Stickle, P.E. Sobol, K.D. Bomben, Handbook of X-ray Photoelectron Spectroscopy, Physical Electronics Inc. Minnesota (1995)

${ }^{33}$ S. Andres, C. Pettenkofer, F. Speck, T. Seyller; J. Appl. Phys. 103, 2008, $103720_{\text {A }}$
Christian Pettenkofer 20.1.14 15:17

Formatiert: Standard, Abstand Nach: 12

Christian Pettenkofer 20.1.14 15:17

Formatiert: Schriftart:Nicht Kursiv 